\title{
Secretion of glucagon-like peptide-1 in patients with type 2 diabetes mellitus: systematic review and meta-analyses of clinical studies
}

\author{
S. Calanna • M. Christensen • J. J. Holst • B. Laferrère • \\ L. L. Gluud • T. Vilsbøll • F. K. Knop
}

Received: 2 November 2012 / Accepted: 10 January 2013 /Published online: 3 February 2013

(C) Springer-Verlag Berlin Heidelberg 2013

\begin{abstract}
Aims/hypothesis We carried out a systematic review of clinical studies investigating glucagon-like peptide-1 (GLP-1) secretion in patients with type 2 diabetes and non-diabetic controls and performed meta-analyses of plasma total GLP1 concentrations during an OGTT and/or meal test.

Methods Random effects models for the primary metaanalysis and random effects meta-regression, subgroup and regression analyses were applied.

Results Random effects meta-analysis of GLP-1 responses in 22 trials during 29 different stimulation tests showed that patients with type 2 diabetes $(n=275)$ and controls without type 2 diabetes $(n=279)$ exhibited similar responses of total GLP-1 ( $p=\mathrm{NS}$ ) as evaluated from peak plasma concentrations (weighted mean difference [95\% CI] $1.09 \mathrm{pmol} / 1$ $[-2.50,4.67])$, total AUC (tAUC) $(159 \mathrm{pmol} / 1 \times \min [-270$,
\end{abstract}

Electronic supplementary material The online version of this article (doi:10.1007/s00125-013-2841-0) contains peer-reviewed but unedited supplementary material, which is available to authorised users.

S. Calanna • M. Christensen · J. J. Holst • L. L. Gluud •

T. Vilsbøll $\cdot$ F. K. Knop $(\bowtie)$

Diabetes Research Division, Department of Internal Medicine,

Gentofte Hospital, University of Copenhagen,

Niels Andersens Vej 65,

DK-2900 Hellerup, Denmark

e-mail: filipknop@dadlnet.dk

S. Calanna

Department of Clinical and Molecular Biomedicine,

University of Catania, Catania, Italy

J. J. Holst • F. K. Knop

Department of Biomedical Sciences, The Panum Institute,

University of Copenhagen, Copenhagen, Denmark

B. Laferrère

Obesity Nutrition Research Center, St Luke's/Roosevelt Hospital Center, Columbia University College of Physicians and Surgeons, New York, NY, USA
589]), time-corrected tAUC (tAUC $\left.\mathrm{min}^{-1}\right)(0.99 \mathrm{pmol} / \mathrm{l}$ $[-1.28,3.27])$, incremental AUC (iAUC) $(-122 \mathrm{pmol} / 1 \times \min$ $[-410,165])$ and time-corrected iAUC (iAUC $\mathrm{min}^{-1}$ ) $(-0.49 \mathrm{pmol} / 1[-2.16,1.17])$. Fixed effects meta-analysis revealed higher peak plasma GLP-1 concentrations in patients with type 2 diabetes. Subgroup analysis showed increased responses after a liquid mixed meal test (peak, tAUC and tAUC $\mathrm{min}^{-1}$ ) and after a $50 \mathrm{~g}$ OGTT (AUC and tAUC $\min ^{-1}$ ), and reduced responses after a solid mixed meal test (tAUC $\min ^{-1}$ ) among patients with type 2 diabetes. Meta-regression analyses showed that $\mathrm{HbA}_{1 \mathrm{c}}$ and fasting plasma glucose predicted the outcomes iAUC and iAUC $\min ^{-1}$, respectively.

Conclusions/interpretation The present analysis suggests that patients with type 2 diabetes, in general, do not exhibit reduced GLP-1 secretion in response to an OGTT or meal test, and that deteriorating glycaemic control may be associated with reduced GLP-1 secretion.

Keywords Glucagon-like peptide-1 (GLP-1) · Gut hormones · Incretin secretion · Meta-analysis · Systematic review $\cdot$ Type 2 diabetes mellitus

$\begin{array}{ll}\text { Abbreviations } \\ \text { DPP-4 } & \text { Dipeptidyl peptidase } 4 \\ \text { FPG } & \text { Fasting plasma glucose } \\ \text { GLP-1 } & \text { Glucagon-like peptide-1 } \\ \text { iAUC } & \text { Incremental AUC } \\ \text { tAUC } & \text { Total AUC }\end{array}$

\section{Introduction}

The incretin hormone glucagon-like peptide-1 (GLP-1) is a 30 -amino acid peptide hormone secreted by enteroendocrine L cells mainly located in the mucosa of the distal part of the 
small intestine and colon [1]. Carbohydrate, fat and protein in the lumen of the gut have been shown to stimulate the secretion of GLP-1 [2-4]. GLP-1 is rapidly inactivated via enzymatic cleavage by dipeptidyl peptidase 4 (DPP-4), and only the intact form seems to retain biological effects in humans [1]. GLP-1 acts as a glucose-dependent stimulator of pancreatic insulin secretion and at the same time it glucose-dependently inhibits pancreatic glucagon secretion [5]. GLP-1 also curbs gastrointestinal motility, increases satiety and reduces food intake $[1,6]$. Patients with type 2 diabetes are characterised by a reduced incretin effect, i.e. impaired amplification of insulin secretion during an OGTT compared with isoglycaemic i.v. glucose infusion [7]. Impaired secretion of GLP-1 has been regarded as one of the potential mechanisms underlying this defect [6]. However, in recent years, it has been debated whether GLP-1 secretion is in fact lower in patients with type 2 diabetes compared with matched healthy controls $[8,9]$.

The aim of the present study was systematically to compile all current data on plasma GLP-1 responses following oral glucose or mixed meal ingestion from clinical studies comparing patients with type 2 diabetes and matched nondiabetic controls. By performing meta-analyses (random effects and fixed effects models) with subgroup analysis and meta-regression analyses of the retrieved data we tested the hypothesis that patients with type 2 diabetes exhibit normal GLP-1 responses.

\section{Methods}

Search strategy for identification of trials Eligible trials were identified by electronic and manual searches in literature references. For the electronic searches, we reviewed the Cochrane Library, Medline, Embase and Web of Science. We made no restrictions regarding the trials' language or year of publication. The search terms included 'glucagonlike peptide-1', 'secretion' and 'diabetes mellitus'. These terms were adjusted to fit the requirements specified in each database. The last search update was 1 May 2012.

Review methods and selection criteria Eligible trials were listed and the inclusion criteria were assessed independently by all authors. We excluded studies which used non-specific assays that cross-react with the major proglucagon fragment $[2,10-12]$, those which did not provide enough data [13] and those which dealt with intact GLP-1 only [14-19]. Excluded trials were listed with the reason for exclusion. Two authors extracted data independently. We included studies investigating adult patients with type 2 diabetes and matched non-diabetic controls reporting plasma total GLP-1 responses (peak plasma levels and/or integrated responses and/or integrated incremental responses) following an OGTT and/or meal test. All included trials reported clinically relevant outcome measures and provided clear descriptions of GLP-1 secretory stimuli and the specific assays used for determining plasma GLP-1 concentrations. If applicable, we contacted the authors of the original publications to obtain additional data.

Statistical analyses Data analyses were performed using Stata version 11 (StataCorp, College Station, TX, USA). We used random effects models for the primary analyses because we expected clinical heterogeneity between trials (owing to different patient populations and intervention regimens). Results of the meta-analyses were expressed as weighted mean differences for continuous outcomes and relative risks for dichotomous outcomes, both with $95 \%$ confidence intervals and with $I^{2}$ values as markers of intertrial heterogeneity. We repeated the meta-analyses, using fixed effects models, to test the robustness of the results after attributing less weight to small trials. We reported the results of the fixed effects meta-analyses if they differed from those of the random effects models. Regression analysis of funnel plot asymmetry allowed us to assess any evidence of publication bias and small study effects (Egger's test). Subgroup analysis examined separately the GLP-1 secretion following either oral glucose or meal tests. Random effects meta-regression was applied to investigate whether BMI, age, $\mathrm{HbA}_{1 \mathrm{c}}$ or fasting plasma glucose (FPG) could predict the size of the estimated intervention effects. We performed post hoc subgroup analyses for variables associated with inter-trial heterogeneity.

\section{Results}

Included studies We identified 1,120 potentially eligible references during the initial searches. After excluding duplicates and clearly irrelevant references, we retrieved 33 relevant references (flow chart for identification and selection of included studies in electronic supplementary material [ESM] Fig. 1). Of these references, 22 [20-41] (29 datasets) fulfilled our inclusion criteria (trial characteristics are shown in ESM Table 1). The included studies were all published as full paper articles between 1996 and 2012. The patient characteristics (Table 1) and the diagnostic criteria for type 2 diabetes were very similar across trials. Total GLP-1 was measured by antiserum 89390 in 17 of the papers, by the RIA kit from Millipore (Billerica, MA, USA) in four papers $[21,22,34,36]$, and by the RIA kit from Phoenix Pharmaceutical (Belmont, CA, USA) in one paper [30]. We received additional data that were not described in the published reports from five of the included trials [21, 29-31, 41]. The included studies reported total GLP-1 plasma responses in 14 OGTTs (one $25 \mathrm{~g}$ OGTT, one $40 \mathrm{~g} / \mathrm{m}^{2}$ 
Table 1 Characteristics of the study participants

\begin{tabular}{|c|c|c|}
\hline Variable & $\begin{array}{l}\text { Patients with type } \\
2 \text { diabetes }\end{array}$ & $\begin{array}{l}\text { Non-diabetic } \\
\text { controls }\end{array}$ \\
\hline$n(\%$ male $)$ & $275(54 \%)$ & $279(53 \%)$ \\
\hline Age (years) & $55(18-76)$ & $49(19-71)$ \\
\hline BMI $\left(\mathrm{kg} / \mathrm{m}^{2}\right)$ & $33(23-46)$ & $30(22-46)$ \\
\hline FPG $(\mathrm{mmol} / \mathrm{l})$ & $8.0(5.0-12.0)$ & $5.0(4.6-6.0)$ \\
\hline Fasting plasma insulin (pmol/1) & $112(29-292)$ & $74(34-181)$ \\
\hline $\mathrm{HbA}_{1 \mathrm{c}}(\%)$ & $7.2(5.2-9.2)$ & $5.5(4.0-6.4)$ \\
\hline $\mathrm{HbA}_{1 \mathrm{c}}(\mathrm{mmol} / \mathrm{mol})$ & $55(33-77)$ & $37(20-46)$ \\
\hline Fasting GLP-1 (pmol/1) & $12.5(5.8-23.4)$ & $12.6(4.9-31.0)$ \\
\hline
\end{tabular}

Data are means with ranges in parentheses

OGTT, four $50 \mathrm{~g}$ OGTTs, seven $75 \mathrm{~g}$ OGTTs and one $125 \mathrm{~g}$ OGTT) and 15 mixed meal tests (11 solid mixed meal tests and four liquid mixed meal tests ranging from $1,090 \mathrm{~kJ}$ [260 kcal] to 3,487 kJ [833 kcal]) (ESM Table 1).

GLP-1 responses We performed a random effects metaanalysis including 554 participants (275 patients with type 2 diabetes and 279 non-diabetic controls) from 22 trials with 29 datasets. This random effects meta-analysis of plasma GLP-1 responses found that patients with type 2 diabetes and non-diabetic controls exhibited similar total GLP-1 responses when evaluated from peak plasma concentrations (weighted mean difference $[95 \% \mathrm{CI}] 1.09 \mathrm{pmol} / 1[-2.50$, 4.67]), total AUC (tAUC) (159 $\mathrm{pmol} / 1 \times \min [-270,589])$ (Fig. 1), time-corrected tAUC (tAUC $\left.\min ^{-1}\right)(0.99 \mathrm{pmol} / 1$ $[-1.28,3.27])$, incremental AUC (iAUC) $(-122 \mathrm{pmol} / 1 \times \mathrm{min}$ $[-410,165])$ (ESM Fig. 2) and time-corrected iAUC (iAUC $\left.\mathrm{min}^{-1}\right)(-0.49 \mathrm{pmol} / 1[-2.16,1.17])$. The regression analysis did not show any clear evidence of bias or small study effects (Egger's test, $p>0.1$ for all analyses).

A repeat of the initial meta-analyses with fixed effects models confirmed the results of the primary meta-analyses, with the only exception that peak plasma total GLP-1 responses were higher in patients with type 2 diabetes compared with non-diabetic controls (1.79 pmol/1 [0.07, 3.50]) (Fig. 2).

Subgroup analyses showed increased responses after a liquid mixed meal test and a $50 \mathrm{~g}$ OGTT, and reduced responses after a solid mixed meal test, among patients with type 2 diabetes compared with controls (Table 2).

Random effects meta-regression of the primary metaanalysis found no independent effects of age, BMI, FPG or $\mathrm{HbA}_{1 \mathrm{c}}$ on any variables of GLP-1 responses with the exceptions that $\mathrm{HbA}_{1 \mathrm{c}}$ predicted the outcome iAUC and FPG predicted iAUC $\mathrm{min}^{-1}$. Post hoc subgroup analysis, dividing the trials into two groups according to $\mathrm{HbA}_{1 \mathrm{c}}$ levels (subgroup one: trials with mean $\mathrm{HbA}_{1 \mathrm{c}} \leq 7.5 \%$ [58.5 mmol/mol]; subgroup two: trials with mean $\mathrm{HbA}_{1 \mathrm{c}}>7.5 \%$ [ $\left.>58.5 \mathrm{mmol} / \mathrm{mol}\right]$ ), showed a negative influence of $\mathrm{HbA}_{1 \mathrm{c}}$ levels on integrated incremental plasma GLP-1 responses (iAUC) (Fig. 3).

\section{Discussion}

The present study constitutes a systematic examination of GLP-1 secretory data from clinical studies and provides evidence that patients with type 2 diabetes, in general, do not exhibit reduced GLP-1 secretion in response to oral glucose or meal tests. Thus, the present data do not support the notion of a lower secretion of GLP-1 in type 2 diabetes, which was one of the incentives to provide exogenous GLP-1 as substitution therapy for patients with type 2 diabetes [42].
Fig. 1 Meta-analysis of plasma total GLP-1 responses during an OGTT or meal test evaluated from tAUC (pmol/1×min) using a random effects model. WMD, weighted mean difference. Capital letters indicate different GLP-1 secretory stimuli in the same study

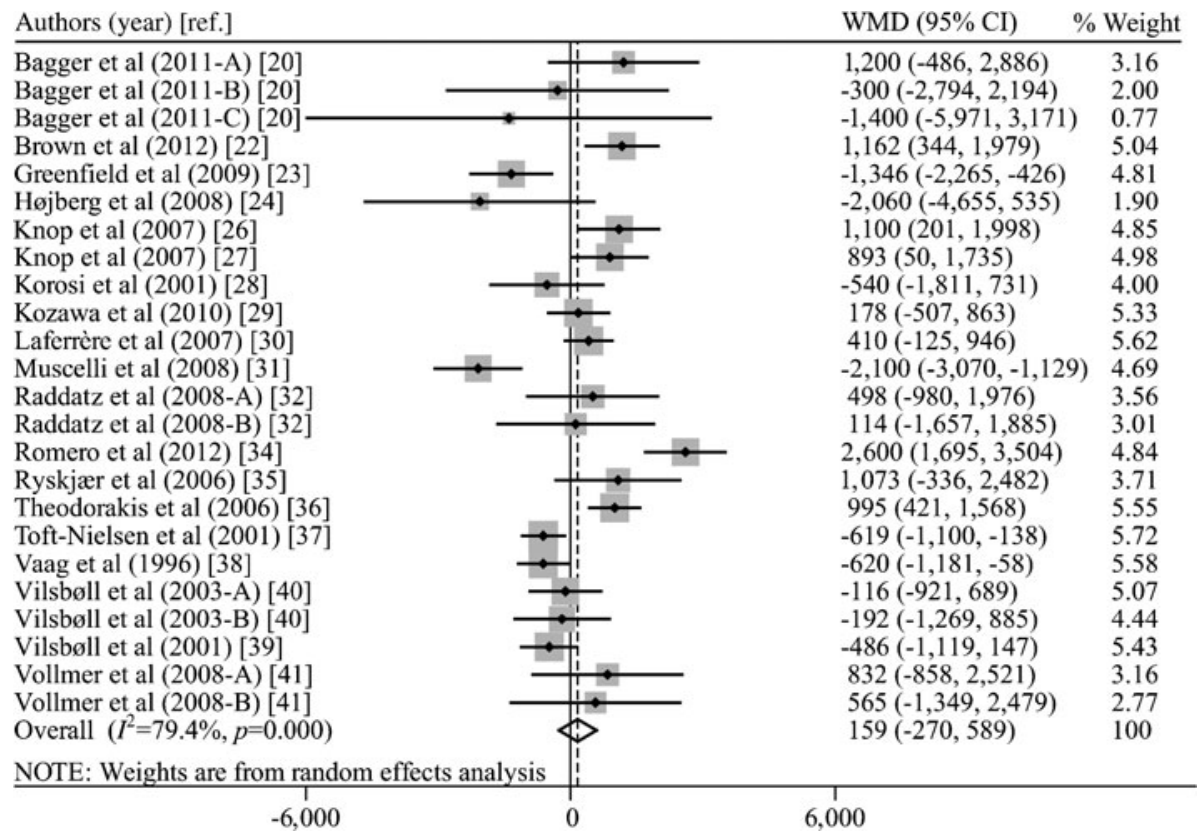


Fig. 2 Meta-analysis of peak plasma total GLP-1 concentrations (pmol/l) during an OGTT or meal test using a fixed effects model. WMD, weighted mean difference. Capital letters indicate different GLP-1 secretory stimuli in the same study

\begin{tabular}{|c|c|c|c|}
\hline Authors (year) [ref.] & & WMD ( $95 \%$ CI $)$ & $\%$ Weight \\
\hline Bagger et al (2011-A) [20] & 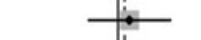 & $3.0(-7.5,13.5)$ & 2.64 \\
\hline Bagger et al (2011-B) [20] & & $-18.0(-53.3,17.3)$ & 0.24 \\
\hline Bagger et al (2011-C) [20] - & & $-9.0(-66.9,48.9)$ & 0.09 \\
\hline Bose et al (2010) [21] & & $5.4(0.4,10.4)$ & 11.68 \\
\hline Jørgensen et al (2012) [25] & . & $3.0(0.2,5.8)$ & 38.60 \\
\hline Knop et al (2007) [26] & & $8.1(-2.8,19.0)$ & 2.47 \\
\hline Knop et al (2007) [27] & & $6.6(-3.1,16.3)$ & 3.13 \\
\hline Kozawa et al (2010) [29] & $\longrightarrow$ & $0.3(-9.1,9.6)$ & 3.35 \\
\hline Laferrère et al (2007) [30] & $\rightarrow$ & $-9.3(-15.2,-3.3)$ & 8.25 \\
\hline Muscelli et al (2008) [31] & $\longrightarrow$ & $-18.2(-28.6,-7.9)$ & 2.74 \\
\hline Raddatz et al (2008-A) [32] & & $-8.9(-37.9,20.1)$ & 0.35 \\
\hline Raddatz et al (2008-B) [32] & & $0.8(-33.2,34.8)$ & 0.25 \\
\hline Ryskjær et al (2006) [35] & 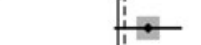 & $7.9(-0.6,16.4)$ & 4.09 \\
\hline Vilsbøll et al (2003-A) [40] & & $1.4(-7.0,9.8)$ & 4.19 \\
\hline Vilsbøll et al (2003-B) [40] & - & $1.2(-10.4,12.8)$ & 2.19 \\
\hline Vilsbøll et al (2001) [39] & $\rightarrow$ & $-5.0(-11.2,1.2)$ & 7.65 \\
\hline Vollmer et al (2008-A) [41] & $\rightarrow$ & $11.2(4.5,17.9)$ & 6.62 \\
\hline Vollmer et al (2008-B) [41] & $i$ & $5.5(-8.6,19.6)$ & 1.47 \\
\hline Overall $\left(I^{2}=65.4 \%, p=0.000\right)$ & 6 & $1.8(0.1,3.5)$ & 100 \\
\hline
\end{tabular}

hoc subgroup analysis showed that increasing levels of $\mathrm{HbA}_{1 \mathrm{c}}$ associated negatively with integrated incremental plasma GLP-1 responses (iAUC). In line with this, studies investigating newly diagnosed patients with type 2 diabetes and relatively low $\mathrm{HbA}_{1 \mathrm{c}}$ often find normal plasma GLP-1 responses during OGTTs [21, 22, 26-28, 30], meal tests [29, 32, 33, 35] or both [41]. Also, some studies, in well-regulated patients $\left(\mathrm{HbA}_{1 \mathrm{c}}<7 \%\right.$ [53 mmol/mol] $)[20,25,34,36]$ with a relatively short duration of type 2 diabetes ( $<48$ months) $[20,34,36]$ have shown increased GLP-1 responses after OGTTs $[20,36]$ or liquid meal tests $[25,34]$. Indeed, in one of these studies, Theodorakis et al [36] showed increased numbers of $\mathrm{L}$ cells in the duodenum of newly diagnosed patients with type 2 diabetes as well as increased plasma GLP-1 levels between 20 and $80 \mathrm{~min}$ after a $75 \mathrm{~g}$ OGTT, which supports the notion of normal

Table 2 Subgroup analyses

\begin{tabular}{llll}
\hline Variable & Liquid meal & 50 g OGTT & Solid meal \\
\hline Peak plasma GLP-1 levels $(\mathrm{pmol} / \mathrm{l})$ & $2.9(0.1,5.6)$ & $1.1(-2.3,4.4)$ & $0.5(-3.1,4.1)$ \\
& $p=0.03$ & $p=\mathrm{NS}$ & $p=\mathrm{NS}$ \\
tAUC $(\mathrm{pmol} / \mathrm{l} \times \mathrm{min})$ & $1,722(1,016,2,430)$ & $661(257,1,065)$ & $-282(-568,3)$ \\
& $p<0.01$ & $p=0.01$ & $p=\mathrm{NS}$ \\
tAUC $\min ^{-1}(\mathrm{pmol} / \mathrm{l})$ & $10.8(6,15.6)$ & $3.3(1.4,5.3)$ & $-1.5(-2.9,-0.1)$ \\
& $p<0.01$ & $p=0.01$ & $p=0.03$ \\
\hline
\end{tabular}

Data are expressed as weighted mean difference with $95 \% \mathrm{CI}$ in parentheses

Negative weighted mean difference values represent a lower GLP-1 response, and positive values reflect a higher GLP-1 response in patients with type 2 diabetes compared with non-diabetic controls

GLP-1 responses evaluated from iAUC and time-corrected iAUC (iAUC $\mathrm{min}^{-1}$ ) did not display any significant differences in any of the examined subgroups, and these data are not reported in the table

GLP-1 responses during $25 \mathrm{~g}, 75 \mathrm{~g}$ and $125 \mathrm{~g}$ OGTTs did not display any significant differences and these data are not reported in the table

NS, non-significant $p$ value $(>0.05)$ 
Fig. 3 Subgroup analysis, according to mean $\mathrm{HbA}_{1 \mathrm{c}}$ levels, of plasma total GLP-1 responses during an OGTT or meal test evaluated from iAUC (pmol/1 $\times$ min) using a random effects model. Subgroup 1 is composed of trials with mean $\mathrm{HbA}_{1 \mathrm{c}} \leq 7.5 \%(\leq 58.5 \mathrm{mmol} / \mathrm{mol})$ and subgroup 2 is composed by trials with mean $\mathrm{HbA}_{1 \mathrm{c}}>$ $7.5 \%$ ( $>58.5 \mathrm{mmol} / \mathrm{mol})$. WMD, weighted mean difference. Capital letters indicate different GLP-1 secretory stimuli in the same study

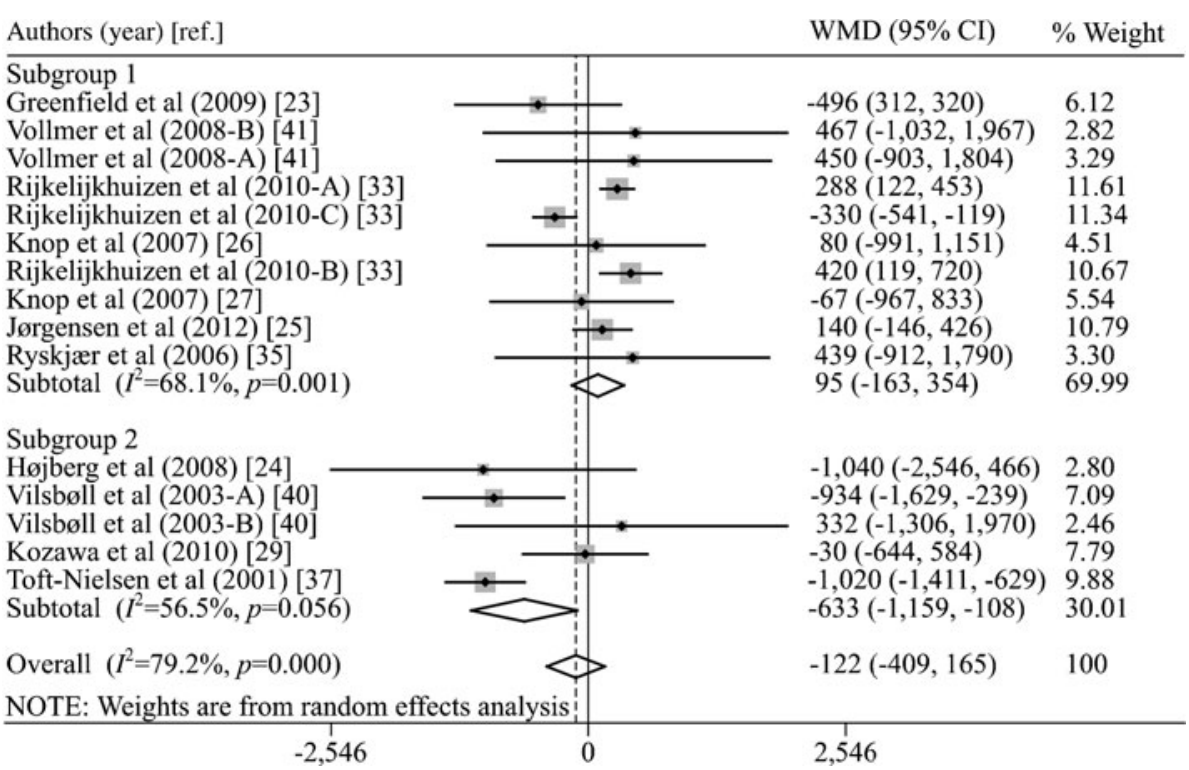

or even higher OGTT or meal-induced plasma GLP-1 responses in the early stages of type 2 diabetes.

More recently, reduced GLP-1 responses have also been observed after OGTTs in mainly male, severely obese (BMI $>35 \mathrm{~kg} / \mathrm{m}^{2}$ ) patients with type 2 diabetes [23, 31]. A negative association between GLP-1 responses and BMI has been reported in some of the mentioned studies, which found reduced secretion of GLP-1 in patients with type 2 diabetes [31, 37]. However, when looking at the collective publications, as in the present meta-regression analysis, BMI was not found to be a determinant of GLP-1 secretion.

Interestingly, our fixed effects meta-analysis that attributes less weight to smaller trials revealed higher peak plasma GLP-1 concentrations in patients with type 2 diabetes, and subgroup analysis showed increased responses after a liquid mixed meal test and after a $50 \mathrm{~g}$ OGTT among type 2 diabetic patients. These findings, combined with the negative impact of $\mathrm{HbA}_{1 \mathrm{c}}$ and FPG on integrated incremental GLP-1 responses (iAUC) and time-corrected integrated incremental GLP-1 responses (iAUC $\min ^{-1}$ ), may suggest that the GLP-1 secretion profile could change shape during the progression of type 2 diabetes. As a parallel to the insulin resistance-associated hyperinsulinaemic state in the early stages of type 2 diabetes (followed by insulin hyposecretion in the later stages), we hypothesise that compensatory L cell secretion of GLP-1 may exist in the early stages of type 2 diabetes, followed by L cell 'exhaustion' when the disease progresses and glycaemic control deteriorates, as suggested from in vitro and animal experiments [43]. Nevertheless, it should be noted that fixed effects meta-analysis should be interpreted with care due to the large heterogeneity between the included trials; consequently, the study effect size differs not only by the number of participants in each study (sampling error) but also by other unaccounted variables. Thus, the notion of $\mathrm{L}$ cell exhaustion being part of the natural history of type 2 diabetes remains speculative.

As mentioned, patients with type 2 diabetes have consistently been characterised by a reduced incretin effect. Our findings support the idea that a deterioration in GLP-1 effect, rather than GLP-1 secretion, contributes to this deficiency. Indeed, hyperglycaemia could lead to downregulation of GLP-1 receptor expression on beta cells and 'GLP-1 resistance' as observed in studies in rats [44]. In support of this hypothesis, some of the included trials reported an impaired incretin effect despite normal GLP-1 secretion $[20,21,26,27,30]$ in diabetic patients. These findings could have important implications for the design of new therapies based on activation of the GLP-1 receptor or other modulations of the GLP-1 pathways.

The subgroup analysis was performed to improve understanding of the diverse impact of the different studies. As mentioned above, it showed increased GLP-1 levels after a $50 \mathrm{~g}$ OGTT (evaluated from peak plasma GLP-1, integrated GLP-1 responses [tAUC], time-corrected integrated GLP-1 responses [tAUC $\left.\min ^{-1}\right]$ ) and a liquid meal test (evaluated from tAUC and tAUC $\mathrm{min}^{-1}$ ) in patients with type 2 diabetes, whereas reduced time-corrected integrated incremental plasma GLP-1 responses (iAUC $\min ^{-1}$ ) after a solid meal test were observed. The observed differences between liquid and solid meal tests could, at least in part, be due to variations in absorption of the nutrients in patients with type 2 diabetes. Indeed, delayed gastric emptying of solid meals, a frequently observed aspect of long-standing autonomic neuropathy in diabetic patients [45], might increase absorption in the proximal intestine, resulting in less food reaching the distal intestine where the GLP-1-secreting L cells are more numerous. By contrast, gastric emptying of liquid nutrients has been reported to be abnormally rapid in 'early' type 2 diabetes [46], and this could help to explain the observed 
increased plasma GLP-1 responses following an OGTT/liquid meal in the patients with type 2 diabetes included in the present study.

Another explanation for the diverse GLP-1 responses among patients with type 2 diabetes may be rooted in the different drugs used to treat the disease. Indeed, metformin $[43,47]$ and bile acid sequestrants, like colesevelam [48], have been demonstrated to increase GLP1 secretion. Thus, changing patterns in the use of glucose-lowering drugs during the past 20 years and different pre-study washout periods (from 12 to $72 \mathrm{~h}$ in 12 studies, and 3 weeks in the others) could bias results in favour of a higher or lower GLP-1 secretion in type 2 diabetic patients treated with these drugs. Thus, clearly, further studies are necessary to assess the impact of different glucose-lowering drug treatments on GLP-1 secretion.

In the present meta-analysis, studies using non-specific assays that may cross-react with other proglucagon moieties, e.g. the major proglucagon fragment, were excluded. Nevertheless, one may suspect that our results could be affected by the fact that three different assays were used to measure total GLP-1 in plasma across the included studies. The majority of the studies assessed total GLP-1 by a highly accurate RIA (antiserum 89390) that is specific for the amidated C-terminal of the GLP-1 molecule and reacts equally with intact GLP-1(7-36)amide and the Nterminally truncated primary metabolite GLP-1(9-36)amide. This assay includes ethanol extraction of plasma to remove unspecific interference. Five studies [21, 22, 30, 34, 36] used different RIA kits, which may include reactivity towards GLP-1(7-37) and its metabolites, and where extraction is not performed. As a result, plasma levels may vary considerably between assays. In line with this notion, a recent study of available total GLP-1 assays showed that some assays measured higher levels while others measured lower levels in otherwise identical samples from patients with type 2 diabetes [49]. Nevertheless, all three assays included in the present analysis have shown very low cross-reactivity with glucagon $(<0.2 \%)$ and/or GLP-2 $(<0.01 \%)$, and detection levels of $\leq 3 \mathrm{pmol} / \mathrm{l}$. Importantly, all the studies included appropriate control groups of nondiabetic individuals.

In 2011, Nauck et al provided a narrative review about GLP-1 secretion [9], which also included a meta-analysis (pooled estimates, random effects model) of ten studies (13 datasets) [16, 26, 31, 35-37, 39-41] comparing plasma GLP-1 responses (iAUCs) in patients with type 2 diabetes $(n=189)$ and matched healthy controls $(n=217)$ after an OGTT or a meal test. In the present study, we went further and performed both random and fixed effects models, besides evaluating inter-trial heterogeneity, meta-regression and subgroup analyses. Also, in addition to the incremental integrated responses of plasma total GLP-1 (iAUC) evaluated by Nauck et al [9], the present study includes data on peak plasma levels, integrated total responses (tAUC) as well as time-corrected integrated responses (taking into account the duration of the individual meal test/OGTT), providing a detailed analysis of several variables describing GLP-1 secretion following an OGTT and/or a meal test.

Whereas our meta-analysis only includes data on plasma total GLP-1, the meta-analysis by Nauck et al [9] also included some data on plasma intact GLP-1 [16]. Intact GLP-1 levels are indicators of the concentration of active hormone in the peripheral circulation available for signalling via the endocrine (blood-borne) pathway. Because active GLP-1 is subject to rapid degradation by the enzyme DPP- 4 almost immediately upon its release $\left(t_{1 / 2} \sim 1.5 \mathrm{~min}\right)$ [50], only $\sim 10 \%$ of intact GLP-1 actually reaches the systemic circulation [51], thereby reducing the possibility of detecting a small difference between responses in the peripheral circulation. Thus, studies evaluating 'GLP-1 secretion' using intact GLP-1 assays are often compromised by readings below the lower limit of detection and by large variations in peripheral measurements; furthermore, intact GLP-1 assays have been shown to yield conflicting results due to high inter-assay variations [49]. In addition, changes in intact GLP-1 concentrations during smaller meals or low-dose OGTTs are often undetectable [40]. By contrast, plasma concentrations of total GLP-1 include any intact, active hormone plus the inactive primary metabolite of GLP-1 [GLP-1(9-36)], which is cleared more slowly from the blood (primarily through the kidneys) [52]. Thus, total GLP-1 levels are better indicators of the overall secretory response.

In contrast to the mentioned analysis by Nauck et al, we did not include separate datasets from studies that divided plasma GLP-1 responses into early- or late-phase responses (i.e. the two datasets from Theodorakis et al [0-20 min, 20$120 \mathrm{~min}$ ] [36] and the two datasets from Vilsbøll et al [0 $30 \mathrm{~min}, 30-180 \mathrm{~min}$ ] [40]), but instead unified the results to provide overall plasma GLP-1 responses and to avoid duplicate analyses of data from the same study. Despite the methodological differences between the present study and the meta-analysis provided by Nauck et al [9], both analyses support the contention of preserved GLP-1 secretory responses to oral glucose and liquid meals in type 2 diabetic patients.

We conclude that, in general, patients with type 2 diabetes do not exhibit reduced plasma total GLP-1 responses during oral glucose or liquid meal tests, as previously hypothesised. Nevertheless, deteriorating glycaemic control (high $\mathrm{HbA}_{1 \mathrm{c}}$ ) seems to associate negatively with plasma GLP-1 responses. 
Acknowledgements We thank I. Shimomura [29] (Department of Metabolic Medicine, Graduate School of Medicine, Osaka University, Suita, Japan), J. Kozawa [29] (Department of Metabolic Medicine, Graduate School of Medicine, Osaka University, Suita, Japan), E. Ferrannini [31] (Department of Internal Medicine, Consiglio Nazionale delle Ricerche (CNR), Institute of Clinical Physiology, University of Pisa, Italy) and E. Muscelli [31] (Department of Internal Medicine, Consiglio Nazionale delle Ricerche (CNR), Institute of Clinical Physiology, University of Pisa, Italy), for contributing unpublished data from their studies for further analysis.

Duality of interest The authors declare that there is no duality of interest associated with this manuscript.

Contribution statement SC contributed to the study design, researched the data, contributed to the discussion and wrote the manuscript. MC researched the data, contributed to the discussion, and reviewed and edited the manuscript. JJH contributed to the study design and discussion, and reviewed and edited the manuscript. BL contributed to the study design and the discussion, and reviewed and edited the manuscript. LLG contributed to the study design and discussion, researched the data, and reviewed and edited the manuscript. TV contributed to the study design and discussion, and reviewed and edited the manuscript. FKK designed the study, researched the data, contributed to the discussion, and reviewed and edited the manuscript. FKK is the guarantor of this work and, as such, had full access to all the data in the study and takes responsibility for the integrity of the data and the accuracy of the data analysis. All authors approved the final version.

\section{References}

1. Holst JJ (2007) The physiology of glucagon-like peptide 1. Physiol Rev 87:1409-1439

2. Ørskov C, Jeppesen J, Madsbad S, Holst JJ (1991) Proglucagon products in plasma of noninsulin-dependent diabetics and nondiabetic controls in the fasting state and after oral glucose and intravenous arginine. J Clin Invest 87:415-423

3. Ross SA, Dupre J (1978) Effects of ingestion of triglyceride or galactose on secretion of gastric inhibitory polypeptide and on responses to intravenous glucose in normal and diabetic subjects. Diabetes 27:327-333

4. Tolhurst G, Reimann F, Gribble FM (2012) Intestinal sensing of nutrients. Handb Exp Pharmacol 209:309-335

5. Hare KJ, Vilsbøll T, Asmar M, Deacon CF, Knop FK, Holst JJ (2010) The glucagonostatic and insulinotropic effects of glucagonlike peptide 1 contribute equally to its glucose-lowering action. Diabetes 59:1765-1770

6. Vilsbøll T (2004) On the role of the incretin hormones GIP and GLP-1 in the pathogenesis of type 2 diabetes mellitus. Dan Med Bull 51:364-370

7. Holst JJ, Knop FK, Vilsbøll T, Krarup T, Madsbad S (2011) Loss of incretin effect is a specific, important, and early characteristic of type 2 diabetes. Diabetes Care 34(Suppl 2):S251-S257

8. Meier JJ, Nauck MA (2008) Is secretion of glucagon-like peptide1 reduced in type 2 diabetes mellitus? Nat Clin Pract Endocrinol Metabol 4:606-607

9. Nauck MA, Vardarli I, Deacon CF, Holst JJ, Meier JJ (2011) Secretion of glucagon-like peptide-1 (GLP-1) in type 2 diabetes: what is up, what is down? Diabetologia 54:10-18

10. Nauck MA, Heimesaat MM, Orskov C, Holst JJ, Ebert R, Creutzfeldt W (1993) Preserved incretin activity of glucagon-like peptide 1 [7-36 amide] but not of synthetic human gastric inhibitory polypeptide in patients with type-2 diabetes mellitus. J Clin Invest 91:301-307
11. Fukase N, Igarashi M, Takahashi H et al (1993) Hypersecretion of truncated glucagon-like peptide-1 and gastric inhibitory polypeptide in obese patients. Diabet Med 10:44-49

12. Fukase N, Manaka H, Sugiyama K et al (1995) Response of truncated glucagon-like peptide-1 and gastric inhibitory polypeptide to glucose ingestion in non-insulin dependent diabetes mellitus. Effect of sulfonylurea therapy. Acta Diabetol 32:165-169

13. Cohen AE, Johnston CS (2011) Almond ingestion at mealtime reduces postprandial glycemia and chronic ingestion reduces hemoglobin $\mathrm{A}(1 \mathrm{c})$ in individuals with well-controlled type 2 diabetes mellitus. Metab Clin Exp 60:1312-1317

14. Han SJ, Kim HJ, Choi S-E, Kang Y, Lee KW, Kim DJ (2010) Incretin secretion and serum DPP-IV activity in Korean patients with type 2 diabetes. Diabetes Res Clin Pract 89:e49-e52

15. Lee S, Yabe D, Nohtomi K et al (2010) Intact glucagon-like peptide-1 levels are not decreased in Japanese patients with type 2 diabetes. Endocr J 57:119-126

16. Salinari S, Bertuzzi A, Asnaghi S, Guidone C, Manco M, Mingrone G (2009) First-phase insulin secretion restoration and differential response to glucose load depending on the route of administration in type 2 diabetic subjects after bariatric surgery. Diabetes Care 32:375-380

17. Dar MS, Chapman WH 3rd, Pender JR et al (2012) GLP-1 response to a mixed meal: what happens 10 years after Roux-en-Y gastric bypass (RYGB)? Obes Surg 22:1077-1083

18. Lugari R, Dell'Anna C, Ugolotti D et al (2000) Effect of nutrient ingestion on glucagon-like peptide 1 (7-36 amide) secretion in human type 1 and type 2 diabetes. Horm Metab Res 32:424-428

19. Milton JE, Sananthanan CS, Patterson M, Ghatei MA, Bloom SR, Frost GS (2007) Glucagon-like peptide-1 (7-36) amide response to low versus high glycaemic index preloads in overweight subjects with and without type II diabetes mellitus. Eur J Clin Nutr 61:1364-1372

20. Bagger JI, Knop FK, Lund A, Vestergaard H, Holst JJ, Vilsbøll T (2011) Impaired regulation of the incretin effect in patients with type 2 diabetes. J Clin Endocrinol Metab 96:737-745

21. Bose M, Teixeira J, Olivan B et al (2010) Weight loss and incretin responsiveness improve glucose control independently after gastric bypass surgery. J Diabetes 2:47-55

22. Brown RJ, Walter M, Rother KI (2012) Effects of diet soda on gut hormones in youths with diabetes. Diabetes Care 35:959-964

23. Greenfield JR, Farooqi IS, Keogh JM et al (2009) Oral glutamine increases circulating glucagon-like peptide 1, glucagon, and insulin concentrations in lean, obese, and type 2 diabetic subjects. Am J Clin Nutr 89:106-113

24. Højberg PV, Vilsbøll T, Zander M et al (2008) Four weeks of nearnormalization of blood glucose has no effect on postprandial GLP1 and GIP secretion, but augments pancreatic B cell responsiveness to a meal in patients with type 2 diabetes. Diabet Med 25:1268-1275

25. Jørgensen NB, Jacobsen SH, Dirksen C et al (2012) Acute and long-term effects of Roux-en-Y gastric bypass on glucose metabolism in subjects with type 2 diabetes and normal glucose tolerance. Am J Physiol Endocrinol Metab 303:E122-E131

26. Knop FK, Vilsbøll T, Højberg PV et al (2007) Reduced incretin effect in type 2 diabetes: cause or consequence of the diabetic state? Diabetes 56:1951-1959

27. Knop FK, Vilsbøll T, Madsbad S, Holst JJ, Krarup T (2007) Inappropriate suppression of glucagon during OGTT but not during isoglycaemic i.v. glucose infusion contributes to the reduced incretin effect in type 2 diabetes mellitus. Diabetologia 50:797-805

28. Korosi J, McIntosh CH, Pederson RA et al (2001) Effect of aging and diabetes on the enteroinsular axis. J Gerontol A Biol Sci Med Sci 56:M575-M579

29. Kozawa J, Okita K, Imagawa A et al (2010) Similar incretin secretion in obese and non-obese Japanese subjects with type 2 diabetes. Biochem Biophys Res Commun 393:410-413 
30. Laferrère B, Heshka S, Wang K et al (2007) Incretin levels and effect are markedly enhanced 1 month after Roux-en-Y gastric bypass surgery in obese patients with type 2 diabetes. Diabetes Care 30:1709-1716

31. Muscelli E, Mari A, Casolaro A et al (2008) Separate impact of obesity and glucose tolerance on the incretin effect in normal subjects and type 2 diabetic patients. Diabetes 57:1340-1348

32. Raddatz D, Nolte W, Rossbach C et al (2008) Measuring the effect of a study meal on portal concentrations of glucagon-like peptide 1 (GLP-1) in non diabetic and diabetic patients with liver cirrhosis: transjugular intrahepatic portosystemic stent shunt (TIPSS) as a new method for metabolic measurements. Exp Clin Endocrinol Diabetes 116:461-467

33. Rijkelijkhuizen JM, McQuarrie K, Girman CJ et al (2010) Effects of meal size and composition on incretin, alpha-cell, and beta-cell responses. Metabolism 59:502-511

34. Romero F, Nicolau J, Flores L et al (2012) Comparable early changes in gastrointestinal hormones after sleeve gastrectomy and Roux-en-Y gastric bypass surgery for morbidly obese type 2 diabetic subjects. Surg Endosc 26:2231-2239

35. Ryskjær J, Deacon CF, Carr RD et al (2006) Plasma dipeptidyl peptidase-IV activity in patients with type-2 diabetes mellitus correlates positively with $\mathrm{HbA1c}$ levels, but is not acutely affected by food intake. Eur J Endocrinol 155:485-493

36. Theodorakis MJ, Carlson O, Michopoulos S et al (2006) Human duodenal enteroendocrine cells: source of both incretin peptides, GLP-1 and GIP. Am J Physiol Endocrinol Metab 290:E550-E559

37. Toft-Nielsen MB, Damholt MB, Madsbad S et al (2001) Determinants of the impaired secretion of glucagon-like peptide1 in type 2 diabetic patients. J Clin Endocrinol Metab 86:37173723

38. Vaag AA, Holst JJ, Vølund A, Beck-Nielsen HB (1996) Gut incretin hormones in identical twins discordant for non-insulindependent diabetes mellitus (NIDDM) - evidence for decreased glucagon-like peptide 1 secretion during oral glucose ingestion in NIDDM twins. Eur J Endocrinol 135:425-432

39. Vilsbøll T, Krarup T, Deacon CF, Madsbad S, Holst JJ (2001) Reduced postprandial concentrations of intact biologically active glucagon-like peptide 1 in type 2 diabetic patients. Diabetes 50:609-613

40. Vilsbøll T, Krarup T, Sonne J et al (2003) Incretin secretion in relation to meal size and body weight in healthy subjects and people with type 1 and type 2 diabetes mellitus. J Clin Endocrinol Metab 88:2706-2713

41. Vollmer K, Holst JJ, Baller B et al (2008) Predictors of incretin concentrations in subjects with normal, impaired, and diabetic glucose tolerance. Diabetes 57:678-687

42. Zander M, Madsbad S, Madsen JL, Holst JJ (2002) Effect of 6week course of glucagon-like peptide 1 on glycaemic control, insulin sensitivity, and beta-cell function in type 2 diabetes: a parallel-group study. Lancet 359:824-830

43. Lim GE, Huang GJ, Flora N, LeRoith D, Rhodes CJ, Brubaker PL (2009) Insulin regulates glucagon-like peptide-1 secretion from the enteroendocrine L cell. Endocrinology 150:580-591

44. Xu G, Kaneto H, Laybutt DR et al (2007) Downregulation of GLP-1 and GIP receptor expression by hyperglycemia: possible contribution to impaired incretin effects in diabetes. Diabetes 56:1551-1558

45. Cavallo-Perin P, Aimo G, Mazzillo A, Riccardini F, Pagano G (1991) Gastric emptying of liquids and solids evaluated by acetaminophen test in diabetic patients with and without autonomic neuropathy. Riv Eur Sci Med Farmacol 13:205-209

46. Phillips WT, Schwartz JG, McMahan CA (1992) Rapid gastric emptying of an oral glucose solution in type 2 diabetic patients. J Nucl Med 33:1496-1500

47. Mannucci E, Tesi F, Bardini G et al (2004) Effects of metformin on glucagon-like peptide-1 levels in obese patients with and without type 2 diabetes. Diabetes Nutr Metabol 17:336-342

48. Beysen C, Murphy EJ, Deines K et al (2012) Effect of bile acid sequestrants on glucose metabolism, hepatic de novo lipogenesis, and cholesterol and bile acid kinetics in type 2 diabetes: a randomised controlled study. Diabetologia 55:432-442

49. Bak M, Pedersen J, Knop FK, et al (2012) Accuracy and sensitivity of commercially available methods for the measurement of human glucagon like peptide 1 (GLP-1). Diabetes 61(Suppl 1):A481-482

50. Hansen L, Deacon CF, Ørskov C, Holst JJ (1999) Glucagon-like peptide-1-(7-36)amide is transformed to glucagon-like peptide-1(9-36)amide by dipeptidyl peptidase IV in the capillaries supplying the $L$ cells of the porcine intestine. Endocrinology 140:5356-5363

51. Holst JJ, Deacon CF (2005) Glucagon-like peptide-1 mediates the therapeutic actions of DPP-IV inhibitors. Diabetologia 48:612-615

52. Deacon CF, Knudsen LB, Madsen K, Wiberg FC, Jacobsen O, Holst JJ (1998) Dipeptidyl peptidase IV resistant analogues of glucagon-like peptide-1 which have extended metabolic stability and improved biological activity. Diabetologia 41:271-278 